\title{
Rivaroxaban for treatment of heparin-induced thrombocytopenia after cardiac surgery: A case report
}

\author{
Laure Abouchakra, MD, ${ }^{\mathrm{a}}$ Ziad Khabbaz, MD, ${ }^{\mathrm{b}}$ Samah Abouassi, MD, ${ }^{\mathrm{a}}$ and Georges Badaoui, MD, ${ }^{\mathrm{a}}$ Beirut, \\ Lebanon
}

See related commentary on pages e20-2.

Heparin-induced thrombocytopenia (HIT) is a highly prothrombotic disorder mediated by strong platelet-activating antibodies against multimolecular complexes of platelet factor 4 and heparin, leading to consumptive thrombocytopenia and potentially devastating thromboembolic complications. Three alternative anticoagulants have been approved for the treatment of HIT: lepirudin, argatroban, and danaparoid sodium. These agents are mainly considered niche products, however, with few or no other non-HIT indications, and they have limited availability in many countries. They are expensive, require a hospital stay for parenteral administration and frequent monitoring, and can cause serious bleeding. ${ }^{1} \mathrm{We}$ report our first experience with the use of a novel oral anticoagulant, rivaroxaban, to treat a case of HIT-associated thrombosis after coronary artery bypass grafting.

\section{CLINICAL SUMMARY}

A 53-year-old man with a history of diabetes mellitus was admitted for unstable angina and was treated with aspirin, clopidogrel, and enoxaparin sodium. He underwent a cardiac catheterization and subsequent coronary artery bypass grafting with left internal thoracic artery-left anterior descending artery, saphenous vein graft (SVG)-diagonal, and SVGright coronary artery anastomoses. After an uneventful hospital stay, the patient was discharged home on postoperative day 5 with a platelet count of 239,000 cells $/ \mathrm{mm}^{3}$.

On postoperative day 6 , the patient came to the emergency department with reports of dyspnea and chest pain. The platelet count on readmission, 5 days after the last heparin exposure, was 75,000 cells $/ \mathrm{mm}^{3}$, and it continued to decrease to a nadir of 25,000 cells $/ \mathrm{mm}^{3}$ on postoperative day 11 . A cardiac catheterization revealed a thrombotic image in the SVG-right coronary artery graft (Figure 1). Anti-platelet factor 4-heparin antibodies were tested by a rapid lateral-flow

\footnotetext{
From the ${ }^{\mathrm{a}}$ Division of Cardiology, Hotel-Dieu de France Hospital and Saint Joseph University, Beirut, Lebanon; and the ${ }^{\mathrm{b}}$ Division of Cardiothoracic Surgery, HotelDieu de France Hospital and Saint Joseph University, Beirut, Lebanon.

Disclosures: Authors have nothing to disclose with regard to commercial support.

Received for publication March 19, 2015; revisions received April 12, 2015; accepted for publication April 18, 2015; available ahead of print June 6, 2015.

Address for reprints: Georges Badaoui, MD, Division of Cardiology, Hotel-Dieu

de France Hospital, A. Naccache Ave, Achrafieh, Beirut, Lebanon (E-mail:

badaouig@hotmail.com).

J Thorac Cardiovasc Surg 2015;150:e19-20

$0022-5223 / \$ 36.00$

Copyright (c) 2015 by The American Association for Thoracic Surgery

http://dx.doi.org/10.1016/j.jtcvs.2015.04.054
}

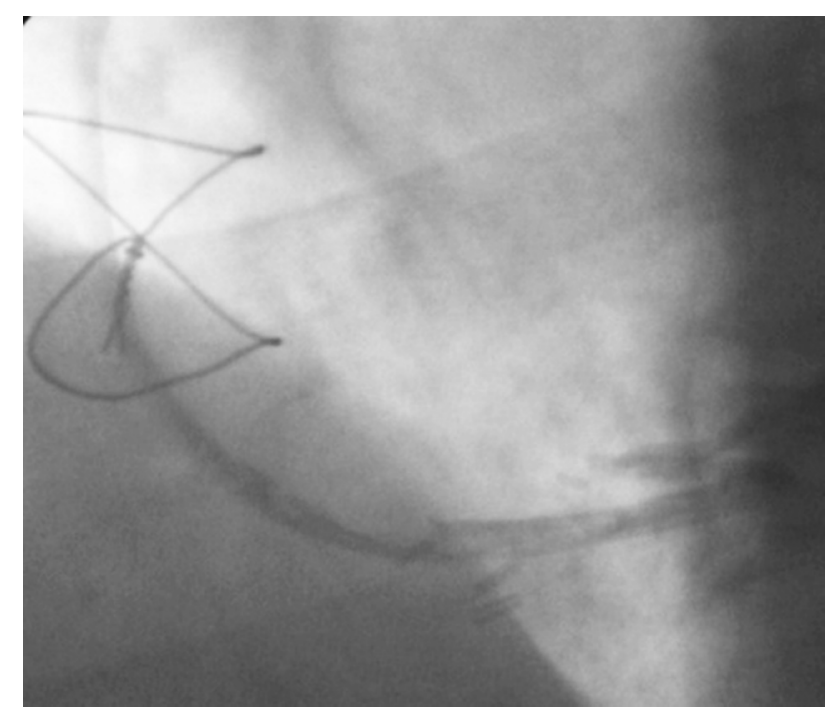

FIGURE 1. A Thrombotic image visualized in the saphenous vein graftright coronary artery.

immunoassay (STic EXPERT HIT; Diagnostica Stago SAS, Asnières, France), which yielded a strongly positive result, and the diagnosis of HIT was highly suspected.

Duplex ultrasonographic examination revealed a circumferential fresh mural thrombus of the carotid bulb with a subsequent $40 \%$ stenosis but no deep venous thrombosis in the lower limbs.

In view of the lack of lepirudin availability in the hospital and the surrounding facilities, the patient was started on rivaroxaban at the dosage of $20 \mathrm{mg}$ twice daily. He had a gradual recovery and was finally discharged home with a platelet count of 120,000 cells $/ \mathrm{mm}^{3}$. A coronary angiogram performed 1 month later showed disappearance of the thrombotic image in the SVG-right coronary artery graft (Figure 2). A repeated ultrasonographic examination showed fading of the previous thrombus in the carotid bulb. The platelet count reached 204,000 cells $/ \mathrm{mm}^{3}$, and no serious bleeding complications had been noted by then.

\section{DISCUSSION}

In adult cardiac surgery, HIT occurs in $1.0 \%$ to $2.4 \%$ of patients and is one of the causes of perioperative SVG failure. The diagnosis of HIT in this population remains a difficult one for several reasons. First, a major decrease in platelet count by $40 \%$ to $50 \%$ occurs universally during the first 72 hours after surgery and can persist beyond the first 5 days. In addition, as many as $25 \%$ to $70 \%$ of patients have development of anti-platelet factor 4-heparin antibodies during the first 10 days after cardiac surgery, but 


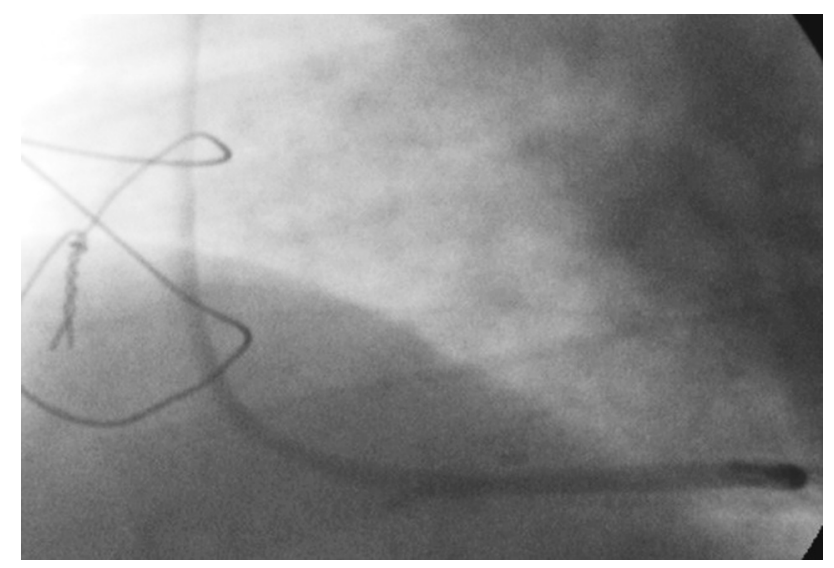

FIGURE 2. Patent saphenous vein graft-right coronary artery after rivaroxaban treatment.

only a minority of these patients have development of clinically evident HIT. $^{2}$ Unfortunately, we had no access to washed-platelet functional assays, such as the carbon 14labeled serotonin release assay; nevertheless, our patient had a high pretest probability for HIT (a score of 7 according to the 4Ts scoring system ${ }^{3}$ ), along with a positive antibody test result, and so we decided to initiate alternative nonheparin anticoagulation because delays in treatment are associated with an initial $5 \%$ to $10 \%$ daily risk of thrombosis, amputation, or death. Currently approved parenteral direct thrombin inhibitors were not available at that time in our institution, however, and we therefore resorted to using rivaroxaban in the management of our patient.

Rivaroxaban is an oral, direct factor $\mathrm{X}$ inhibitor that has shown efficacy in the treatment of venous and arterial thromboembolism. The key advantages of its use for the treatment of HIT include ease of administration (fixed dose), absence of a need for laboratory monitoring, longer half-life and lower cost relative to parenteral agents. Moreover, it obviates the need for a warfarin-direct thrombin inhibitor overlap period and thus is expected to reduce the length of hospitalization. ${ }^{4}$ After initiation of rivaroxaban treatment, careful attention is necessary, not only to bleeding but also to potential worsening of thrombocytopenia, because there have been rare reports of thrombocytopenia with novel oral anticoagulant use. ${ }^{5}$

\section{Conclusions}

This case is one of the first experiences with using rivaroxaban as an off-label alternative to the standard treatments for HIT. Although the findings cannot establish the efficacy and safety of this drug for this indication-a prospective study is currently being conducted for that purpose ${ }^{4}$-they seem promising in the setting of an easier strategy to treat HIT.

\section{References}

1. Warkentin TE. HIT: treatment easier, prevention harder. Blood. 2012;119: 1099-100.

2. Pouplard C, May MA, Iochmann S, Amiral J, Vissac AM, Marchand M, et al. Antibodies to platelet factor 4-heparin after cardiopulmonary bypass in patients anticoagulated with unfractionated heparin or a low-molecular-weight heparin: clinical implications for heparin induced thrombocytopenia. Circulation. 1999; 99:2530-6.

3. Cuker A, Gimotty PA, Crowther MA, Warkentin TE. Predictive value of the 4Ts scoring system for heparin-induced thrombocytopenia: a systematic review and meta-analysis. Blood. 2012;120:4160-7.

4. Linkins LA, Warkentin TE, Pai M, Shivakumar S, Manji RA, Wells PS, et al. Design of the rivaroxaban for heparin-induced thrombocytopenia study. J Thromb Thrombolysis. 2014;38:485-92.

5. Mima Y, Sangatsuda Y, Yasaka M, Wakugawa Y, Nagata S, Okada Y. Acute thrombocytopenia after initiating anticoagulation with rivaroxaban. Intern Med. 2014; $53: 2523-7$

\section{EDITORIAL COMMENTARY}

\section{Another off-label novel oral anticoagulant to HIT cardiac surgery patients}

Cesario F. Bianchi, MD, PhD, ${ }^{a}$ and Orlando Petrucci, $\mathrm{MD}, \mathrm{PhD}^{\mathrm{b}}$

\footnotetext{
From the ${ }^{a}$ Brazilian Biosciences National Laboratory, National Center for Research in Energy and Materials, Campinas, Brazil; and the ${ }^{\mathrm{b}}$ Department of Surgery, Faculty of Medical Science, State University of Campinas, Campinas, Brazil.

Disclosures: Authors have nothing to disclose with regard to commercial support

Received for publication May 5, 2015; accepted for publication May 6, 2015; available ahead of print June 3, 2015.

Address for reprints: Cesario F. Bianchi, MD, PhD, National Center for Research in Energy and Materials, Brazilian Biosciences National Laboratory, Rua Giuseppe Maximo Scolfaro, 10000, Caixa Postal 6192, CEP 13083-970, Campinas, São Paulo, Brazil (E-mail: cesariobianchi@gmail.com).

J Thorac Cardiovasc Surg 2015;150:e20-2

$0022-5223 / \$ 36.00$

Copyright (C) 2015 by The American Association for Thoracic Surgery

http://dx.doi.org/10.1016/j.jtcvs.2015.05.024
}

See related article on pages e19-20.

Heparin-induced thrombocytopenia (HIT), one of the immune-mediated thrombocytopenia and thrombosis disorders, is characterized by a decline in platelet count between 4 to 14 days ("typical onset") after initial exposure to mainly unfractionated heparin leading to the detection of anti-platelet factor 4-heparin immune complex IgG (PF4-Hep-IgG). In patients previously exposed to heparin 